Scientiæ studia, São Paulo, v. 8, n. 4, p. 571-96, 2010

\title{
st \\ O método de análise cartesiano e o seu fundamento
}

\author{
César Augusto Battisti
}

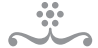

RESUMO

Este artigo examina certos pontos essenciais do método cartesiano e seu fundamento. (1) Dado que Descartes elege a análise como seu método, é a partir da antiga tradição dos geômetras gregos que devemos examiná-la. (2) Seu método não é, entretanto, de natureza matemática. A análise põe às claras o modo de a razão conhecer, ilustrado por essa ciência. (3) A reflexão cartesiana distingue metodologia de epistemologia. Relações de dependência entre objetos são, em geral, estabelecidas a partir do relativo e do complexo, dada a primazia metodológica destes em relação ao absoluto e ao simples. (4) Um dos modos mais profundos de justificar essa primazia do dependente - e, com isso, justificar o método de análise, na medida em que é um procedimento contra a corrente - liga-se à tese cartesiana de que compreender algo é compreender a sua causa, visto que todo existente existe como efeito. (5) O método de análise, portanto, pode assumir, como é de sua essência, o efeito como dado e proceder "para cima" em busca da causa, e seu fundamento está no axioma da identidade entre a causa e a razão, causa sive ratio.
\end{abstract}

Palavras-Ghave • Geração. Descartes. Método de análise. Pappus. Matemática. Razão. Causa.

\section{Descartes E a ANÁLIse dos ANTigos}

Nas diferentes e principais ocasiões em que Descartes discute temas relativos à sua metodologia, algum tipo de referência à análise dos antigos está sempre presente (cf. Descartes, 1985 , p. 25-8, 1983a, p. 37, 4. , 1983c, p. 166-8; AT, 10, p. 373-4, AT 6, p. 18, 20, AT, 9, p. 121-3). ${ }^{1}$ Paralelamente, em $A$ geometria encontramos indicativos inequívocos da utilização da análise, por exemplo, nas passagens do primeiro livro que descrevem suas principais etapas (cf. AT, 6, p. 372), e especialmente na presença da famosa frase que enuncia a instauração da análise. Diz Descartes nessa ocasião: “se desejarmos

1 As citações dos textos de Descartes serão feitas a partir de edições em língua portuguesa (quando possível), acompanhadas das referências da edição standard das obras completas do filósofo, editadas por Charles Adam e Paul Tannery (AT). Não havendo indicação da edição portuguesa, a tradução é minha. Da mesma forma, traduções de textos de outros autores, a menos que haja indicação expressa, são de minha autoria 
resolver algum problema, devemos primeiramente considerá-la [a sua resolução] como já feita" (AT, 6, p. 372). Da mesma forma que, para os antigos, o ato de instauração da análise começava com a seguinte proclamação: "suponhamos o problema resolvido" ou "suponhamos o que é procurado como já tendo sido feito", encontramos em Descartes, na mesma situação, frases como "eu suponho a coisa como já feita" (cf. AT, 6, p. 382, 413). Também se percebe nessa obra de Descartes grande familiaridade com a Coleção matemática de Pappus, que contém a principal descrição dos métodos de análise e de síntese dos geômetras gregos. ${ }^{2}$ Tendo em conta o teor dessas referências e desses indicativos, parece não haver dúvidas quanto à tese de que Descartes é um legítimo praticante do método de análise geométrica e, como tal, filia-se a essa tradição metodológica (cf. Battisti, 2002).

Uma vez admitida essa tese, não é fácil, entretanto, determinarmos o significado e o alcance dessa filiação cartesiana. E isso por diferentes razões, algumas das quais destacaremos a seguir em função do propósito do presente texto.

A primeira delas diz respeito às diferenças e ao distanciamento entre a matemática da época de Descartes e a dos gregos, de sorte que o método dos gregos dificilmente poderia ser estendido à álgebra nascente ou à geometria cartesiana sem modificações ou sem adaptações. Os matemáticos do início da modernidade, ao pretenderem recuperar o método dos antigos, tiveram de adaptá-lo aos "novos tempos”. Sob esse aspecto, a análise que aparece em $A$ geometria já não poderia, rigorosamente falando, ser a mesma da dos gregos.

A segunda leva em conta a ousada pretensão cartesiana de estender a análise para além das disciplinas matemáticas, de modo a universalizar o método para todas as áreas do saber. Ora, essa proposta é exclusivamente cartesiana e não deixa de constituirse em um desafio inédito e surpreendente. Embora os algebristas modernos pretendessem fazer algo semelhante, sua extrapolação metodológica ainda respeitava os limites da matemática, contrariamente à atitude de Descartes, que afirma explicitamente ter empregado a análise na metafísica ${ }^{3}$ e pretender propor um único método para todas as áreas.

2 A Coleção matemática de Pappus contém, no início de Livro 7? (Pappus, 1982, p. 477-8), a principal descrição que conhecemos da análise e da síntese dos antigos. Além dessa fonte, há apenas outros dois textos: uma interpolação no Livro 13 dos Elementos e um texto de Heron (conservado em árabe) em seu comentário ao Livro 2 dos Elementos. É relevante o fato de que Pappus é um dos raros autores textualmente citados por Descartes em suas obras, o que comprova que o filósofo teve em suas mãos a obra pappusiana supracitada. Descartes cita (AT, 6, p. 377-9) um longo trecho do Livro 7 da Coleção (Pappus, 1982, p. 506-10), conforme a tradução latina de Federico Commandino, trecho que dará origem ao célebre "problema de Pappus". Outro problema (Prop. 72) do mesmo Livro z (Pappus, 1982 , p. 6o6-8) é examinado por Descartes no Livro 3 de $A$ geometria (AT, 6, p. 462-3).

3 Dizem as Segundas respostas: “quanto a mim, segui somente a via analítica em minhas Meditações” (Descartes, 1983c, p. 167; AT, 9, p. 122). 
A terceira delas, relacionada à anterior, diz respeito à única descrição que Descartes nos oferece dos métodos de análise e de síntese, no final das Segundas respostas, cujo vocabulário e horizonte a partir do qual ela é discutida e apresentada não é matemático. Embora esse fato seja indicativo da extrapolação matemática do método, ele não deixa de constituir-se em um entrave ao exame de um tema que, a princípio, aparece como exclusivamente matemático. ${ }^{4}$ De todo modo, esse problema pode ser levantado mesmo em relação aos algebristas modernos: o método, antes que matemático, é apenas geométrico e, portanto, trata-se de saber se ele pode ser discutido e descrito de forma a englobar outras áreas, mesmo que pertencentes à matemática.

Além disso, por razões internas ao seu sistema e em razão dos objetivos de sua filosofia, Descartes não poderia simplesmente assumir um método estabelecido por outros. É por demais conhecida a natureza crítica da sua filosofia, sua postura revolucionária e a perspectiva de um começo radical: como aceitar um paradigma metodológico de antemão instituído, quando se trata exatamente de "começar tudo novamente desde os fundamentos" (Descartes, 1983b, p. 85; AT, 7, p. 17, AT, 9, p. 13) e, portanto, de rejeitar tudo o que estiver, de alguma forma, previamente dado?

Finalmente, é preciso considerar a atitude cartesiana frente aos praticantes da análise. Embora faça referência aos geômetras gregos e aos algebristas com admiração e apreço, em nenhum momento Descartes pensa dever reconhecer sua dívida para com eles ou permanecer preso à tradição dos analistas, no sentido de ter de assumir determinados princípios ou elementos teóricos previamente elaborados, cuja justificação deveria ser buscada na própria tradição. Descartes tampouco pretende melhorar ou aperfeiçoar o método existente, e não age como defensor de uma tradição. Ao contrário, é um praticante do método de análise sem sentir-se tributário dos geômetras gregos, diferentemente de Viète, que se apresenta como analista e propõe-se como tarefa desenvolver e aprimorar o método herdado. 5

Todas essas razões, entretanto, ainda que tenham sido apresentadas como dificuldades à compreensão da tese da filiação metodológica cartesiana, deixam de apresentar-se como tais tão logo avançarmos outra tese, por vezes enunciada, mas geralmente inserida em contextos diferentes do que será apresentado aqui. Trata-se da tese

4 Por outro lado, alguém poderia argumentar algo semelhante em relação a Pappus: a descrição pappusiana não parece ser mais matemática que a cartesiana.

5 Viète intitula sua álgebra de "arte analítica” (ars analytice) e, por meio dessa identificação, pretende mostrar que, no fundo, não há diferença entre os procedimentos metodológicos empregados na resolução de problemas geométricos e aqueles empregados na resolução dos problemas algébricos. Viète assume como seu objeto de estudo recuperar o método de análise apresentado por Pappus e combiná-lo com o método de Diofanto. Apresentar essa "arte analítica" é a intenção central do autor, expressa na pequena e fundamental obra Introdução à arte analítica (cf. Viète, 1970). 
de que, para Descartes, em algum sentido que teremos que explicar mais adiante, $o$ método de análise não é um método de natureza matemática, embora possa ser dito geométrico, porque emergiu no interior da ciência geométrica, ou de origem matemática, no sentido de que a matemática é o seu horizonte de aparecimento ou de emergência. O método não poderá, contudo, ser afirmado como matemático, quando procurarmos buscar suas características fundamentais e sua justificação última. Para Descartes, a matemática ilustra histórica, factual e heuristicamente o método, mas não determina a sua natureza. Essa é a razão pela qual o método poderá ser universalizado e considerado "inédito", dado que se mostrará suficientemente independente do contexto geométrico em que surgiu.

Então, se não é de natureza matemática, de onde a análise provém ou qual a sua origem última? Uma primeira resposta a essa questão, cujo aprofundamento será feito mais adiante, é de uma simplicidade desconcertante e pouco esclarecedora, quanto perigosa e passível de mal-entendidos: o método de análise expressa o modus operandi da racionalidade humana quando voltada à produção do saber; a análise é o método que ilustra, por excelência, o cerne do processo de produção do conhecimento humano em geral. Vejamos o que Descartes afirma sobre isso. Diz ele, na Regra 4,

de fato, vemos bastante bem que os antigos geômetras utilizaram uma espécie de análise, que estendiam à solução de todos os problemas, ainda que não a tenham transmitido à posteridade. E agora floresce um gênero de aritmética, que se chama álgebra, que permite fazer para os números o que os antigos faziam para as figuras. Essas duas coisas não passam de frutos espontâneos dos princípios naturais do nosso método; e não me admiro que tenha sido nessas artes, cujos objetos são muito simples, que eles até aqui cresceram com maior facilidade do que nas outras, onde maiores obstáculos geralmente os costumam abafar, mas onde também, no entanto, se cultivados com sumo cuidado, far-se-ão infalivelmente chegar à perfeita maturidade (Descartes, 1985, p. 25; AT, 10, p. 373).

E logo a seguir em outra passagem que enfatiza a espontaneidade e a naturalidade do método de análise:

Contudo, estou persuadido de que as primeiras sementes de verdades, depositadas pela natureza nos espíritos humanos e por nós abafadas devido à leitura ou à audição quotidianas de tantos erros, tinham tal força naquela rude e simples Antiguidade que os homens, mediante a mesma luz intelectual com que viam haver que preferir a virtude ao prazer e o honesto ao útil, embora ignorassem por- 
que era assim, também chegaram a conhecer as idéias verdadeiras da filosofia e da matemática, sem terem ainda podido alcançar perfeitamente estas mesmas ciências. Na verdade, parece-me que alguns vestígios dessa verdadeira matemática surgem ainda em Pappus e Diofanto, os quais, sem serem dos primeiros tempos, viveram no entanto muitos séculos antes da nossa era. E não me custa acreditar que, ulteriormente, os próprios autores a fizeram desaparecer por uma espécie de astúcia perniciosa (Descartes, 1985, p. 27-8; AT, 10, p. 376).

Por meio desses textos, percebemos que Descartes concebe a análise dos geômetras e algebristas como decorrente da espontaneidade com que a mente resolve os problemas teóricos (e práticos) que coloca. Seu método, por sua vez, embora seja resultado de uma reflexão profunda - e, como tal, é elaborado e não espontâneo -, não deixa de ser um prolongamento dos poderes naturais da razão e um polimento ou aperfeiçoamento do método de resolução de problemas ilustrado pela matemática, cuja abrangência, em razão disso, irá muito além desses campos, podendo "estender-se para fazer brotar verdades a respeito de qualquer assunto" (Descartes, 1985, p. 26; AT, 10, p. 374). E não poderia ser diferente, no caso de Descartes, tendo em conta que um dos objetivos centrais de sua filosofia é estabelecer novos fundamentos para o saber, o método que o produz não poderia provir senão das "primeiras sementes de verdades, depositadas pela natureza nos espíritos humanos" (Descartes, 1985, p. 27; AT, 10, p. 376). Em outras palavras, o método não poderia ter uma procedência externa à razão, tal como ocorre, segundo Descartes, com a lógica que, depois de dar vida própria e independência a suas leis, obriga a razão a segui-las cegamente. O método cartesiano brota da reflexão sobre a matemática como paradigma metodológico e, ao mesmo tempo, da reflexão sobre os poderes resolutivos espontâneos possuídos por nossa razão. A matemática serve de ocasião para que a racionalidade revele seu modo de operar e seus poderes.

Assim, a resposta para esse conjunto de dificuldades parece ser o seguinte: o método de análise cartesiano não é de natureza matemática. A matemática serve de ilustração ao método e, como tal, é uma fonte importante para compreendê-lo. A matemática é o horizonte privilegiado de atuação da razão, graças a suas características inerentes e, por isso, merece lugar de destaque na investigação metodológica do filósofo. Descartes é um praticante da análise, método que espontaneamente emergiu no interior da ciência matemática, mas que deverá ser justificado na medida em que revela o modus operandi de nossa capacidade de conhecer. 


\section{O modus operandi DA RAZÃo}

A afirmação de que a matemática, embora sirva para ilustrar o método de análise, não determina a sua natureza, é uma tese que poderá ser esclarecida a partir de dois pontos fundamentais, quais sejam:

(a) a partir da compreensão do que há de comum entre o modo de ser da matemática e o modo de proceder da razão (quando voltada à produção do conhecimento), de sorte que o primeiro revela e torna-se expressão do segundo;

(b) a partir da compreensão da tese do valor metodológico exclusivo da análise (e não da síntese), ainda que seja a matemática em sua totalidade que é considerada modelo de ciência certa e evidente.

O objetivo aqui é começar a esclarecer tais questões. $\mathrm{O}$ racionalismo cartesiano tem como uma de suas marcas mais profundas a de que tudo o que é passível de ser pensado e conhecido deve ser transparente à faculdade ou ao sujeito que pensa ou conhece. Conhecimento significa, de início, domínio e manipulação das coisas pela capacidade de conhecer. E isso quer dizer:

(1) que a razão só pode lidar com o que se manifesta conforme suas exigências, sendo inadequado pretender considerar algo independentemente dessa manifestação;

(2) que, para serem conhecidos, os objetos devem deixar-se "ver" completamente por ela, apesar da resistência que possam apresentar.

Esses são os princípios mais gerais do que poderíamos chamar, de forma ainda indeterminada, de tese da inteligibilidade ou tese da transparência dos objetos do conhecimento. Tais princípios gerais tomam uma configuração relativamente completa e suficiente ao longo das Regras, principalmente no início da obra, quando o autor oferece uma "teoria da ciência", cujo detalhamento é dado na sequência do texto. Essa teoria da ciência é composta de cinco pontos (aqui apresentados apenas no que nos interessa). Além de uma teoria do método, os outros quatro são os seguintes: a tese da unicidade e do completo domínio da razão; a definição de conhecimento como conhecimento certo e evidente; a indicação das operações mentais (a intuição e a dedução) responsáveis pela sua apreensão; e a estipulação dos requisitos definidores da inteligibilidade dos objetos, a ordem e a medida. 
Descartes inicia as Regras decretando a primazia da mente ou da razão em relação aos objetos do conhecimento. A Regra 1 apresenta a unidade originária da razão e afirma que as ciências, por serem atividade e produto do mesmo e idêntico espírito, não se distinguem enquanto tais e conservam essa unidade originária. A luz natural da razão é condição para o conhecimento das coisas; e, sendo única e sempre a mesma, não sofre a influência da diversidade dos objetos, por mais distintos e diferentes que sejam, não necessitando modificar-se em razão da diferença entre eles. Ao contrário, são eles que devem deixar-se homogeneizar pela unidade da razão: eles devem ser receptivos à sua luz (da mesma forma que as coisas recebem a luz solar) e, como tais, deixam de ser apenas coisas para tornarem-se coisas passíveis de serem iluminadas pela razão. Nesse sentido, a Regra 1 decreta a primeira e mais geral exigência no âmbito cognitivo. Ainda sem dizer em que termos, a regra exige uma primeira adequação dos objetos de conhecimento: eles devem partilhar entre si uma natureza comum (primeiro nível de homogeneização dos objetos) que permitirá serem iluminados e tornarem-se visíveis à mente e manipuláveis por ela.

A Regra 4, por sua vez, trata de estipular tais requisitos mais gerais da inteligibilidade de todo e qualquer objeto, a saber, a ordem e a medida. Todo objeto, diz Descartes, para poder ser tratado pelo intelecto, deve poder ser medido e ordenado pela razão. Essa é a proposta cartesiana de uma mathesis universalis, que estipula os critérios da homogeneização dos objetos entre si. Esses critérios são simultaneamente parâmetros da racionalidade humana. Descartes reconhece que os objetos, de qualquer espécie que sejam, embora os da matemática sejam exemplares, devem preencher determinados requisitos para que a mente possa pensá-los, examiná-los, enfim, conhecêlos. A mente deve, primeiramente, poder medi-los e, para tal, é preciso que os objetos tenham uma "grandeza" (essa noção não se restringe à grandeza matemática) e, sob esta, uma unidade comum de medida. Em segundo lugar, se os objetos são homogêneos ou têm uma natureza comum, o que os distingue é seu grau de complexidade ou de composição. O segundo critério da mathesis é a ordem, visto que as coisas ordenam-se dentro do critério da simplicidade e da dependência: elas formam relações entre si, cujo ordenamento ocorre pela relação de composição e de dependência. Conhecer é, portanto, ordenar e medir os objetos entre si pela razão.

Dada essa caracterização do que entendemos por inteligibilidade dos objetos, fica claro percebermos a razão pela qual a matemática, como diz a Regra 2, é o modelo de conhecimento e apresenta-se como a única que está de acordo com a definição de ciência como conhecimento certo e evidente (cf. Descartes, 1985, p. 14; AT, 10, p. 362). Ela é legitimamente uma ciência, graças ao fato de lidar com objetos "puros e simples" e cujas relações ou deduções estabelecidas são igualmente transparentes à razão. Faz 
parte da natureza (da ontologia) dos objetos matemáticos respeitarem os ditames que a razão impõe aos objetos do conhecimento em geral: eles respeitam desde sempre e "naturalmente" os critérios que são impostos pela mente. Finalmente, a Regra 3 trata das operações inatas da mente, a intuição e a dedução, as quais são responsáveis pela apreensão dos objetos do conhecimento, cujas características foram descritas acima. Descartes estabelece que essas duas operações são suficientes ao propósito apresentado. Elas são responsáveis pela apreensão das relações cognitivas entre os objetos no interior de um campo científico. A intuição permite a apreensão de conhecimentos mais simples e fundamentais, e a dedução permite a construção de cadeias de conhecimentos, a derivação de um conhecimento a partir de outro.

Essas são, em síntese, as razões que fundamentam a tese de que a matemática revela espontaneamente as condições mais gerais da inteligibilidade de todo e qualquer objeto e, como tal, serve de modelo epistemológico às demais ciências. E é a matemática em sua totalidade e de forma indistinta que preenche tais requisitos, independentemente do método utilizado em sua produção. A matemática é certa e evidente não porque foi produzida por este ou aquele método, mas porque preenche os requisitos ontológicos e epistemológicos exigidos na constituição do conhecimento certo e evidente. E ela os preenche naturalmente; às outras ciências, por sua vez, cabe também preenchê-los, custe o que custar.

De todo modo, vale a pena frisar o fato de que, até aqui, não estão em discussão questões metodológicas. As Regras 1, 2 e 3 não tratam de questões metodológicas, uma vez que nelas não figura em algum momento o termo "método" ou seus cognatos, e tampouco a Regra 4, na medida em que apresenta os critérios da ordem e da medida (a mathesis universalis). Tais critérios, repitamos, são exigências epistemológicas e ontológicas, por serem ditadas pela mente e exigidas dos objetos de todas as ciências, mas não determinam o modo como elas são operacionalizadas. E, portanto, quando passamos a discutir o tema da produção do conhecimento, e não apenas o da descrição do que seja conhecimento, a questão não é mais a de definir o que seja a inteligibilidade, mas a de caracterizar o modo como se processa a inteligibilidade, o modo como um objeto desconhecido torna-se inteligível e, por conseguinte, passível de ser conhecido. E é aqui que entra o tema do método. Conhecer já não é apenas apresentar os requisitos para que uma coisa seja transparente à mente, mas estabelecer os procedimentos por meio dos quais isso se efetiva.

As Regras 13 e 14, são exemplares nesse quesito, na medida em que nos oferecem um quadro geral dos elementos envolvidos na atividade de produção do conhecimento. Depois de enunciar, na Regra 12, que tudo o que podemos conhecer é conhecido ou por meio de uma intuição direta, cujas proposições correspondentes "devem ocorrer espontaneamente e não podem ser objeto de investigação" (Descartes, 1985, p. 81; 
AT, 10, p. 428-9), ou por meio de questões, Descartes passa a caracterizar, na Regra 13, o que é uma questão. (Subentende-se aqui que todo conhecimento que não for apreendido diretamente por intuição deve sê-lo por meio de questões. Cabe duvidar de que possamos apreender algo intuitivamente "sem investigação" e que esse algo corresponda a um conhecimento importante).

Uma questão, se perfeitamente compreendida, deve incluir, então, três elementos fundamentais:

(1) deve haver nela algo de desconhecido (devidamente indicado ou nomeado como tal), pois, do contrário, não há o que procurar;

(2) deve haver algo de conhecido ou dado, donde a investigação possa partir ou basear-se;

(3) deve existir uma relação de dependência entre eles, único meio de determinar o procurado a partir do dado.

Diz o texto:

em toda questão, deve haver necessariamente algo de desconhecido, pois, de outro modo, a sua investigação seria inútil; em segundo lugar, esse incógnito tem de ser designado de alguma maneira, pois, de outro modo, não estaríamos determinados a investigá-lo de preferência a qualquer outro objeto; em terceiro lugar, só pode ser designado mediante alguma outra coisa já conhecida (Descartes, 1985 , p. 83; AT, 10, p. 43०).

Há algumas variações quanto à precisão do que contém exatamente uma questão. No final da Regra 12, Descartes diz que, nas questões compreendidas perfeitamente, percebemos "três coisas, a saber: que sinais permitem reconhecer o que se procura, quando ele surgir; que é precisamente naquilo de que o devemos deduzir; e como importa provar que há entre esses objetos uma tal dependência que um não pode de forma alguma mudar quando o outro não muda" (Descartes, 1985, p. 82; AT, 10, p. 429). As considerações que faremos consideram as diferentes caracterizações

Embora haja diferentes elementos envolvidos nessa "teoria das questões", interessa-nos chamar atenção aqui, fundamentalmente, para os elementos básicos que compõem o processo de busca do conhecimento. Conhecer é, no mínimo, lidar com um esquema; o conhecimento é o resultado do equacionamento dos três elementos acima apresentados. E o que é mais surpreendente, à primeira vista, é a presença do desconhecido e o papel fundamental desempenhado por ele. Caso contrário, diz Descartes, não há questão alguma e, portanto, não haverá produção de conhecimento al- 
gum (visto que conhecer é tornar o desconhecido conhecido). O desconhecido, além disso, não poderá ser examinado, nem mesmo mencionado (porque desconhecido), a menos que seja, de alguma forma, nomeado e, sob certo aspecto, já "conhecido" ou determinado. ${ }^{\mathbf{6}}$ Em outras palavras, para determinar o desconhecido, ele deve ser delimitado por condições precisas, de forma a poder ser "visualizado" de preferência a outra coisa e estar prefigurado dentro da complexidade dada, estando-lhe assegurado, portanto, um lugar no interior dela. O exame dessas condições e desses limites deve ser feito desde o início, mas isso supõe também a clara percepção do que a questão fornece como dado ou conhecido, sendo comum enganos como o de supor mais do que é fornecido e o de omitir algo.

A Regra 14, dá continuidade à reflexão apresentada na Regra 13 e traz maior precisão principalmente às etapas que antecedem o tratamento resolutivo propriamente dito. Sob esse ponto de vista, a Regra 14 representa um avanço considerável em relação à anterior. $\mathrm{O}$ primeiro passo consiste na tese da "homogeneização" entre o conhecido e o desconhecido, já antecipada no início da obra, mas agora com o intuito de determinar em cada caso seus pré-requisitos necessários; o segundo afirma que essa determinação procede por meio de uma operação chamada aqui de "comparação", uma comparação entre os objetos envolvidos, cujo objetivo é estabelecer sua natureza comum, traduzida em relações ou proporções, somente possível sob a condição de serem grandezas.

Quanto ao primeiro item, Descartes afirma que, no tratamento de uma questão, quando se pretende "deduzir algo de determinado e desconhecido de outro já conhecido" (o conhecimento é, por assim dizer, a determinação do desconhecido a partir do conhecido), não se deve procurar algo que pertença a "um novo gênero de ser", mas alguma coisa que "participa da natureza daquelas que nos são dadas na proposição" (Descartes, 1985, p. 90; AT, 10, p. 4,38). Esta tese da "homogeneização" do desconhecido ao conhecido é de fundamental importância para a problemática da metodologia, pois representa um preceito básico para a sua aplicabilidade. A Regra 12 já havia antecipado essa tese como ilustrativa da atitude de muitos pesquisadores que, diante das dificuldades, tendem a "procurar algum outro novo gênero de ser antes desconhecido" e, assim, "desviam a inteligência de tudo o que é evidente e a orientam para tudo o que há de mais difícil e, partindo à aventura e errantes pelo vazio das causas múltiplas, esperam encontrar algo de novo" (Descartes, 1985, p. 80; AT, 10, p. 4,27; grifo meu). Ao contrário, conclui a Regra 14, se, para conhecer, tivermos de ir à procura de "algum gênero de ser que nada tenha de semelhante com o que o nosso entendimento até agora viu,

6 O exemplo mais claro da presença desses três elementos é, sem dúvida, uma equação matemática, conforme a simbolização do próprio Descartes: a equação $x^{2}+a x=b^{2}$ apresenta a dependência (relação de igualdade, ao lado das operações de soma e de multiplicação) entre o elemento desconhecido $x$ (e seu composto) e os elementos conhecidos $a$ e b (e seu composto). Não é por outra razão que, em A geometria, a montagem da equação é o coroamento da análise. 
(...) seria preciso ser dotado, para isso, ou de um novo sentido, ou de uma mente divina" (Descartes, 1985, p. 91; AT, 10, p. 439). Não há passagem do conhecido ao desconhecido, se ambos forem, entre si, incomensuráveis.

Essa coparticipação do conhecido e do desconhecido em uma "natureza comum" é requisito fundamental à produção do conhecimento. A homogeneidade entre os diversos objetos possibilita a operação metodológica fundamental que Descartes chamou de "comparação". Decorre da coparticipação em uma mesma natureza a possibilidade e a necessidade de explicitar a relação de dependência ou de determinação entre o que é dado e o que é procurado. Afirma Descartes que é por uma "comparação" que se torna possível passar do conhecido ao desconhecido: "todo o A é B, todo o B é C, portanto, todo o A é $\mathrm{C}$, compara-se entre si o que é procurado e o que é dado, quer dizer, A e C, sob esta relação que um e outro são B" (Descartes, 1985, p. 91; AT, 10, p. 439). Nas comparações mais simples, é imediatamente evidente que "o que se procura e o que é dado participam igualmente de uma certa natureza"; no caso das complexas, "a natureza comum não se encontra nos dois objetos como tal, mas segundo determinadas relações ou proporções em que está envolvida" (Descartes, 1985, p. 92; AT, 10, p. 44,0), fato que exige ações adicionais.

São esses os recursos mais gerais por meio dos quais os objetos podem ser conhecidos uns em função dos outros. Eles garantem a aplicabilidade do princípio metodológico da homogeneidade dos objetos relacionados em uma questão e, portanto, a possibilidade de sua comparação e determinação. Garantem, em resumo, que todas as "relações que podem existir entre seres do mesmo gênero devem reportar-se a dois itens, a saber, a ordem e a medida" (Descartes, 1985, p. 101; AT, 10, p. 451). Nesse sentido, Descartes não apenas retoma a proposta de uma mathesis universalis, mas fornece os principais procedimentos característicos do modo de produção humana de conhecer e, por conseguinte, do método que propõe.

Dentre as características que pretendemos ter destacado, há duas que são fundamentais aqui. Primeiro, a impossibilidade de derivar-se um objeto desconhecido a partir de outro (conhecido), a menos que ambos tenham uma natureza comum, de sorte que o conhecimento pode ocorrer somente se os objetos envolvidos pertençam ao mesmo "gênero de ser"; segundo, o fato fundamental de que o desconhecido cumpre uma função indispensável no jogo ou no processo de produção do conhecimento, de modo que, embora conhecer signifique determinar o desconhecido pelo que já se conhece, isso não implica que procedemos do conhecido ao desconhecido.

E é isso que pretendemos destacar aqui, acima de tudo. Em toda produção do saber, o desconhecido precisa fazer parte do processo desde a configuração inicial. Tomá-lo em consideração é aceitar sua "presença”, desde o início. Ele, portanto, deve prefigurar no esquema de produção do conhecimento. A tese da homogeneidade garante, 
de antemão, uma primeira espécie de prefiguração do desconhecido. Por ser homogêneo ao conhecido, isto é, por possuir, com ele, uma medida comum e estabelecer um ordenamento segundo o critério da simplicidade, o desconhecido, sob este aspecto, já é "conhecido" e pode ter alguma determinação antecipada. Por isso, ele poderá ser designado de algum modo, tal como na álgebra designamos antecipadamente as incógnitas. Em segundo lugar, dado que é ele que é dependente e é ele que será determinado pelo conhecido, essa dependência deve ser revelada pela estrutura que o envolve e, portanto, devemos encontrar, nela, pistas dessa relação. Caso contrário, ele será inacessível.

Do ponto de vista metodológico, portanto, o desconhecido ocupa um papel inicial fundamental. Logo, há uma distinção entre a dependência epistemológica entre os objetos de certo domínio, determinada pelo critério da simplicidade e avalizada pela teoria das operações mentais, e o ordenamento dos objetos no processo de conhecer. Embora o conhecido seja epistemologicamente independente e anterior ao desconhecido - este último sendo dependente daquele -, não se segue que essa dependência imprima uma determinada direção metodológica. Métodos distintos poderiam respeitar igualmente as exigências epistemológicas decorrentes da noção de dependência.

Feitas essas considerações, cabe apontar algumas razões que justificam, de forma mais definitiva, o lugar e o papel desempenhado pelo desconhecido na produção do conhecimento e que, finalmente, como veremos mais adiante, constituirão os motivos pelos quais Descartes elege a análise como seu método, porque ela representa o modo de a razão operar quando conhece.

Especialmente na Regra 6, Descartes afirma que, quando consideramos as coisas, não em sua natureza isoladamente, mas à medida que as "comparamos" entre si para conhecê-las umas a partir das outras, elas podem ser ditas "absolutas" ou "relativas". Absoluto é "tudo o que contém em si a natureza pura e simples do que trata uma questão, por exemplo, tudo o que é considerado como independente, causa, simples, universal, uno" (Descartes, 1985, p. 34; AT, 10, p. 381). Relativo, por sua vez, é

o que participa desta mesma natureza ou, ao menos, de algum dos seus elementos; por isso, pode referir-se ao absoluto, e dele deduzir-se mediante certa série; mas, além disso, encerra no seu conceito outras coisas, que chamo relações; assim, é tudo o que se diz dependente, efeito, composto, particular, múltiplo, desigual, dissemelhante, oblíquo etc. (Descartes, 1985, p. 34; AT, 10, p. 382).

Percebemos, aqui, a divisão entre coisas ditas relativas e coisas ditas absolutas, bem como a particularidade revelada pelas coisas relativas. A causa e o simples representam o absoluto, cujas características marcantes são a independência e a precedência epistemológica. A causa, por exemplo, embora seja causa de um efeito (nesse caso, 
poderia ser dita correlativa ao efeito), é diferente e independente dele; o simples, ainda que componha o complexo, é também independente dele e logicamente anterior a ele. Por isso, Descartes não diz que o absoluto pode referir-se ao relativo. Ao contrário, é o relativo que revela o absoluto; e, portanto, "pode referir-se ao absoluto", graças à sua natureza relativa, graças às relações que mantêm com ele. Faz parte do efeito, do composto e do múltiplo revela a causa, o simples e o uno. Em razão disso, o método terá como fim a busca, antes de tudo, do que é absoluto, "o segredo de toda a arte consiste em buscarmos com diligência em todas as coisas o que há de mais absoluto" (Descartes, 1985, p. 34; AT, 10, p. 382).

Elejamos a causalidade como paradigmática dessa relação entre absoluto e relativo, porque a relação causal assumirá, mais tarde, o papel predominante. Embora seja evidente que é o efeito que é determinado pela causa - e pela causa eficiente, única e total, como Descartes dirá mais tarde -, certo é que a causa, pura e simplesmente, não facilita a apreensão do que dela se segue. Parece que estamos autorizados a dizer que, embora a causa seja suficiente para produzir o efeito - e, portanto, que ela determina a natureza e a existência do efeito -, o exame de alguma coisa qualquer (ainda que a postulemos como causa de algo) não revela os seus efeitos, visto que a compreensão de uma coisa não implica compreendê-la como causa. Implica, contudo, compreendê-la como efeito.

Em outras palavras, pode-se compreender uma coisa sem compreendê-la como causa, mas não podemos compreendê-la sem compreendê-la como efeito. É por isso que Descartes apresentará, na época das Meditações, a causalidade como axioma; e um axioma que privilegia uma direção única. $\mathrm{O}$ axioma afirma, não que tudo o que existe seja causa de algo, mas que tudo o que existe é efeito de algo. Por isso, é "natural" perguntarmos pela causa, e não pelo efeito. Diz o Axioma 1 da Exposição geométrica: "Não há coisa existente da qual não se possa perguntar qual a causa pela qual ela existe", cujo complemento é dado pelo Axioma 3: "Nenhuma coisa, ou perfeição alguma dessa coisa atualmente existente, pode ter o nada, ou uma coisa não existente, como a causa de sua existência" (Descartes, 1983c, p. 172; AT, 7, p. 165, AT, 9, p. 127). Esses axiomas apresentam a famosa tese cartesiana da causa como razão, da identidade entre causa e razão, causa sive ratio. Essa tese, dentro dos objetivos do presente texto, implica duas coisas:

(1) compreender algo ou dar a razão de algo é determinar a sua causa, a causa eficiente;

(2) embora a causa determine ou produza o efeito (uma determinação no sentido da causa para o efeito), é o efeito que exige a causa como elemento determinante de sua inteligibilidade (uma orientação no sentido do efeito para a causa): compreender uma coisa é compreendê-la, antes de tudo, como efeito e como efeito de uma causa Essa exigência é 
válida mesmo para Deus, a partir do que Descartes elabora a tese de que Deus é causa sui.

Nesse sentido, a inteligibilidade de algo parece exigir, não o exame do que lhe segue ou o que dele provém (efeito) mas, sim, o exame do que lhe antecede ou daquilo de onde ele provém (causa). A inteligibilidade de algo não implica a determinação de seus efeitos; ao contrário, não só implica a causa, mas reduz-se à determinação causal. Por isso, a causalidade é a razão das coisas, é ela que produz a inteligibilidade das coisas. Essa causalidade, além disso, é apenas de um tipo e única em seu gênero, a causalidade eficiente. Como diz a terceira meditação, "é coisa manifesta pela luz natural que deve haver ao menos tanta realidade na causa eficiente e total quanto no seu efeito", do que decorre "não somente que o nada não poderia produzir coisa alguma, mas também que o mais perfeito (...) não pode ser uma decorrência ou uma dependência do menos perfeito" (Descartes, 1983b, p. 103-4; AT, 7, p. 4, , AT, 9, p. 32).

Descartes institui, portanto, a causalidade como relação responsável pela inteligibilidade das coisas. Explicar é dar a razão de algo; e dar a razão é fornecer a causa; a inteligibilidade resume-se a isso. Há equivalência entre a causa e a razão, entre a causalidade eficiente e a razão: causa sive ratio; e, por isso, de tudo exige-se uma causa, há uma exigência universal da causa. A causalidade é o âmbito da explicação de qualquer coisa que seja.?

Assim, a causa eficiente (única e total) é suficiente para produzir sozinha e adequadamente o efeito. Ela é também a razão das coisas, pois ela não só produz as coisas, mas é o fundamento da compreensão das coisas. Por isso, as coisas exigem que perguntemos pelas suas causas. Logo, as coisas são, antes de tudo, efeitos que pressupõem causas e exigem que as determinemos. A pergunta pela causa é uma pergunta que nos conduz em uma direção contra a corrente (de trás para frente), da coisa dada (axiomaticamente instituída como efeito) para a causa. O movimento imposto pela noção de inteligibilidade como determinação causal é um movimento que tem um ponto de partida estabelecido, pois toda pergunta sobre algo pode assumir, de antemão, esse algo como efeito.

Tudo o que existe existe como efeito, é um algo-efeito. Compreender algo é compreendê-lo como efeito, isto é, é determinar a sua causa. É isso que implica o axioma da causa e a tese da identidade entre a causa e a razão. E, assim, tudo o que existe, por mais desconhecido que seja, é dado e é dado como efeito.

7 Nem mesmo a causalidade parece fornecer a razão suficiente das coisas. Segundo Carraud (2002), como toda entidade exige uma causa como razão, encaminhamos-nos para a busca da causa ou razão última, Deus, cuja incompreensibilidade originária compromete todo o edifício, por tê-lo por causa primeira. Por isso, ao contrário de Leibniz, o axioma da causa é um princípio de razão, mas não princípio de razão suficiente, conclui o intérprete. 
Vejamos como o método de análise incorpora essas reflexões. O objetivo, aqui, é compatibilizar tais reflexões com as descrições pappusiana e cartesiana da análise.

\section{A DESGRIÇÃo Do MÉTOdo DE ANÁlise}

\subsection{A descrição de Pappus de Alexandria}

A análise é um método empregado pelos geômetras gregos na atividade de resolução de problemas (análise problemática) e de demonstração de teoremas (análise teorética). Sua característica distintiva é a de ser um método que procede, de alguma forma, de trás para frente ou contra a corrente, por partir do fim, assumindo-o como atingido, para chegar a algo anterior, efetivamente dado ou conhecido. Somente depois, por meio de uma etapa complementar (a síntese), procede-se, a partir do que foi alcançado na análise, ao estabelecimento da solução do problema ou da verdade do teorema. ${ }^{8}$

No caso da análise teorética, a etapa analítica começa por assumir como verdadeiro o teorema que deseja provar. A partir dessa pressuposição inicial, ela procura encontrar uma condição anterior, da qual o teorema possa ser derivado e, sucessivamente, outra condição anterior à primeira, até que se chegue a uma verdade já demonstrada ou a um primeiro princípio. Conquistada tal proposição (um axioma ou um teorema já conhecido), procede-se à demonstração do teorema inicial, começando pelos resultados do procedimento anterior e pela inversão de seus passos, até que se tenha cumprido o objetivo (a prova do teorema). Na análise problemática, de forma similar, começa-se por assumir o problema resolvido, isto é, sua solução como dada. A partir dessa pressuposição, procura-se encontrar, sucessivamente, etapas anteriores que possibilitem resolver o problema inicial ou derivar a solução, até ter-se encontrado um ou mais elementos já dados ou passíveis de construção. Atingido esse estágio, será possível proceder efetivamente à resolução do problema, pela inversão de seus passos, começando-se pelas etapas finais do procedimento anterior, até chegarse ao que foi pressuposto inicialmente. 9

O texto de Pappus (c. 3oo d.G.), no início do Livro ₹ de sua Coleção matemática, é a mais completa e a mais informativa das descrições do método de análise e síntese que chegaram até nossos dias. Diz Pappus:

8 Foi comum eliminar dos tratados a etapa analítica (exatamente por ser um procedimento de descoberta). Descartes critica os gregos por isso (cf. Descartes, 1985, p. 28, 1983c, p. 167; AT, 10, p. 373, AT, 7, p. 156, AT, 9, p. 122;).

9 A diferença entre os dois tipos de análise decorre da diferença entre os problemas e os teoremas. Descartes tem plena consciência dessa distinção (cf. Descartes, 1983c, p. 166-7; AT, 7, p. 156, AT, 9, p. 122). 
A análise é o caminho que parte daquilo que é procurado - considerado como se fosse admitido - e segue, em ordem, através de seus concomitantes [consequências], até algo admitido na síntese. Pois, na análise, supomos o que é procurado como já tendo sido feito e investigamos aquilo do qual ele resulta, e de novo qual é o antecedente deste último, até que, no nosso caminhar para trás, alcancemos algo que já é conhecido e primeiro na ordem. A tal procedimento chamamos de análise, por ser uma solução de trás para frente. Na síntese, por outro lado, tomamos como já feito aquilo que na análise foi por último alcançado e, arranjando em sua ordem natural como consequente o que antes era antecedente e conectando-os uns aos outros, chegamos por fim à construção da coisa procurada. E a isso chamamos síntese.

A análise é de duas espécies. Uma procura a verdade, sendo chamada teorética. A outra serve para produzir o que se desejava fazer, e essa é chamada problemática. Na espécie teorética, supomos a coisa procurada como existindo e sendo verdadeira, e então passamos em ordem pelos seus concomitantes [consequências], como se fossem verdadeiros e existentes por hipótese, até algo admitido; então, se aquilo que é admitido é verdadeiro, a coisa procurada é também verdadeira, e a prova será o reverso da análise. Porém, se chegarmos a algo que é falso admitir, a coisa procurada também será falsa. Na espécie problemática, supomos a coisa desejada como sendo conhecida e então passamos, em ordem, pelos seus concomitantes [consequências], como se fossem verdadeiros, até algo admitido. Se a coisa admitida é possível ou pode ser feita, isto é, se ela for o que os matemáticos chamam de dado, a coisa desejada será também possível. A prova será novamente o reverso da análise. Mas se chegarmos a algo impossível de admitir, o problema será também impossível (Pappus apud Hintikka \& Remes, 1983, p. 293o, 1974, p. 8-10).

A descrição de Pappus apresenta várias dificuldades interpretativas, examinadas longamente pelos especialistas, dentre as quais se destaca o problema da natureza dos passos da etapa analítica e de seu aspecto direcional. Os estudiosos têm tradicionalmente procurado, em suas investigações, determinar se a análise consiste em extrair consequências lógicas do pressuposto inicial (do teorema que se pretende provar ou da solução do problema) ou, pelo contrário, se ela procura remontá-lo a suas condições ou aos antecedentes e, com isso, determinar se ela é descendente ou ascendente. Em outras palavras, discutiu-se muito sobre a questão de se a análise é dedutiva (e ascendente somente por opor-se à síntese), ou se é exclusivamente ascendente e não dedutiva. 
Atualmente há uma tendência a considerar o problema da direção da análise um problema mais superficial do que real, dando importância a outros elementos (cf. Hintikka \& Remes, 1974). Segundo essa visão, ao contrário de caracterizarmos a análise e a síntese a partir do sentido de cada uma das etapas e da natureza dos passos proposicionais, deve-se considerá-las a partir da complexidade dos objetos geométricos envolvidos, de suas inter-relações e interdependências. Os passos da análise são de objetos geométricos para objetos geométricos, e não entre verdades ou mesmo entre proposições geométricas. $\mathrm{O}$ analista não tem, portanto, sua atenção voltada para a estrutura formal que se estabelece entre uma proposição e outra, porque atua diretamente sobre o conteúdo apresentado; não se interessa pela direção das relações lógicas entre elas, pois, na verdade, a etapa analítica não tem (ou não precisa ter) direção alguma, simplesmente porque é anterior a qualquer ordenamento propriamente dito ou é a própria descoberta desse ordenamento.

Mesmo assim, a característica mais marcante do método de análise é sua capacidade de lidar com a estrutura do enunciado ou da problemática fornecida e de utilizála da melhor forma, para extrair o máximo de informações de que dispõe. A famosa frase "suponha-se o problema resolvido" ou outra equivalente-que Pappus e os praticantes da análise sempre utilizam no começo da análise (cf. Heath, 1952, p. 437 ss) não é um mero artifício linguístico ou retórico, sem consequência heurística. Por meio dela, a análise considera o desconhecido (o "efeito", o dependente) como dado ou como se fosse conhecido e, com isso, utiliza a sua "presença" e o poder heurístico que fornece. Cabe lembrar que, embora as noções de causa e de efeito sejam estranhas ao âmbito matemático, as relações causais são similares às relações de dependência no interior da matemática. A fecundidade da etapa analítica provém da utilização dos poderes do procurado (desconhecido), da sua força lógica, mas isso não significa que se deve ir do desconhecido em direção ao conhecido, seja extraindo conclusões, seja buscando premissas, como muitos pretenderam. Sendo ambos dados (conhecido e desconhecido), ainda que cada um a seu modo, a análise utiliza-os como melhor lhe aprouver. A postura do analista é a de estabelecer ou de construir relações úteis entre todas as entidades dadas ou disponíveis, no interior da complexidade em exame, tendo sempre em mente que seu objetivo final é a determinação do desconhecido pelo conhecido.

Visto que a análise considera todos os objetos da configuração como dados, a etapa analítica é dita também consistir no exame dessa complexidade dada em direção a seus elementos componentes. É assim que alguns autores caracterizaram a etapa analítica como a via que consiste em ir do complexo ao simples, como é o caso de Philoponus (cf. Hintikka \& Remes, 1974, p. 94,-5). Por razões semelhantes, a análise por vezes foi descrita como o movimento de ida do efeito para a causa e a síntese, ao contrário, da 
causa para o efeito, acepção mantida pelos termos latinos correspondentes "resolutio" e "compositio".

Nesse caso, pode-se dizer que a análise pretende preencher o vão existente entre o que realmente é dado e conhecido e o que é procurado e desconhecido, atuando indistintamente sobre os dois "extremos da cadeia", tanto de forma conjunta quanto separadamente. Assim, a descrição de Pappus da análise como movimento de trás para frente é o reconhecimento de que o fim desejado, estando sob os olhos do analista, é realmente utilizado heuristicamente ao longo do processo analítico, sem nunca perder de vista o fato de ser, na realidade, consequente ou conclusão, cujas premissas devem ser encontradas. Dentro dessa perspectiva, poder-se-ia dizer que a análise é "intencionalmente" um movimento ascendente, como Pappus parece realmente afirmar: a descrição da análise de Pappus reflete a pretensão de buscar os passos dos quais se seguem o teorema e a construção.

Em outras palavras, a singularidade da análise é considerar o fim como dado e perguntar-se de onde ele poderia proceder. Ela tem uma "intenção", uma "lógica" de proceder para trás. A estratégia de resposta a essa pergunta pode variar em função de quais elementos são disponíveis, da familiaridade que o analista tem para com eles, da estrutura da problemática, das indicações ou das sugestões fornecidas pela própria coisa procurada, da facilidade e da necessidade de ampliar-se, por meio de construções, a configuração inicial etc. Parece que é nesse sentido que Aristóteles a compara, na Ética a Nicômaco (III, 1112b 20 ss), ao procedimento empregado na deliberação ou em uma ação prática: "Com efeito, a pessoa que delibera parece investigar e analisar da maneira que descrevemos, como se analisasse uma construção geométrica (...); e o que vem em último lugar na ordem da análise parece ser primeiro na ordem da geração. E se chegamos a uma impossibilidade, renunciamos à busca: por exemplo, se precisamos de dinheiro e não há maneira de consegui-lo; mas se uma coisa parece possível, tratamos de fazê-la" (Aristóteles, 1987, p. 4,6).

Entretanto, a prática geométrica é predominantemente dedutiva, cuja razão principal é que um procedimento rigorosamente ascendente é, se não pouco viável, pelo menos muito limitante, uma vez que a fecundidade e o poder heurístico do método ampliam-se pela utilização conjunta do conhecido e do desconhecido, bem como de todos os axiomas conhecidos e dos resultados já demonstrados anteriormente. Assim, na prática, o geômetra procede dedutivamente tanto a partir do que é dado quanto do que é procurado, apoiando-se seja em um ou em outro, seja em ambos.

Outra característica da análise é sua capacidade de introduzir novos objetos geométricos e, consequentemente, de enriquecer a configuração inicial. Por ocasião do exame de um teorema ou de um problema, a configuração apresentada em sua 
enunciação muitas vezes não é suficiente para que a análise seja conduzida com êxito, tendo necessidade de ampliar a figura por meio de construções auxiliares. Em outros termos, as construções auxiliares são necessárias para o estabelecimento de relações ou de passos intermediários entre os objetos examinados, na tentativa de conectar o que é conhecido com o que é procurado. É comum ser preciso introduzir novos objetos para que a cadeia de dependências entre os elementos do problema seja construída de forma completa e satisfatória.

Na verdade, os geômetras instituem uma entidade básica em meio à qual o método se instala e atua. Ainda que se aplique tanto a teoremas quanto a problemas geométricos, poder-se-ia dizer, entretanto, que o método diz respeito à resolução de problemas (entendidos em um sentido amplo), ou mesmo de questões, de "dificuldades", como dirá Descartes. A atividade de resolução de problemas não pretende examinar uma proposição, relacioná-la a outras ou deduzi-la de verdades já conhecidas. A prova de um teorema é inventada no interior da configuração examinada, é descoberta no interior do problema, sendo que axiomas e teoremas são chamados (por vezes, descobertos) em função desse exame interno. Resolver um problema é, pois, examinar a configuração inicial, compreender as relações que ela esconde, construir outras e preencher o que falta, a partir do que é proposto. O método analítico é uma análise da complexidade dada em forma de problema, complexidade essa aberta ao exterior, mas não subordinada a ele. Um problema (em seu sentido genérico) apresenta uma determinada estrutura constante e pede que se faça algo ou que se determine algo a partir do que é dado.

Todo problema, portanto, é composto de "dados" ou de elementos conhecidos e do que é "procurado" ou desconhecido. Pertencentes a um problema, esses elementos não se encontram desvinculados, mas estão ou devem estar relacionados, de modo que uns podem ser determinados pelos outros. A resolução do problema consiste na determinação dos desconhecidos a partir dos conhecidos. Entretanto, o método de análise (mais exatamente, sua etapa analítica) não procede conforme essa direção “natural" (do conhecido para o desconhecido). Ela faz a pressuposição de que o problema esteja resolvido. Assim, pode pressupor que todos os elementos necessários à sua resolução estejam dados, bem como pode proceder de forma indiscriminada, seja a partir do fim procurado, seja do que realmente é dado. Dessa maneira, se a etapa analítica não estabelece uma ordem - pois, não havendo objetos privilegiados no interior da configuração, não precisa seguir um sentido privilegiado -, por outro lado, por fazer uso constante do fim desejado (do desconhecido), ela é dita proceder de trás para frente. Ela é dita ser uma solução de trás para frente, porque utiliza o fim (o desconhecido, o "efeito"), como um dos elementos dados, juntamente com o que é realmente dado. 


\subsection{A DESGRIÇÃO GARTESIANA}

As segundas respostas contêm a única descrição dos conceitos cartesianos de análise e de síntese (cf. Descartes, 1983c, p. 166-8; AT, 7, p. 155-9, AT, 9, p. 121-3;). ${ }^{10}$ O texto será examinado a partir de uma dificuldade particularmente reveladora do que Descartes compreende por tais conceitos. A dificuldade diz respeito à disparidade existente entre o texto latino, escrito pelo filósofo, e a tradução autorizada feita por Clerselier. Seguem os textos conforme o original latino e a tradução francesa, nessa ordem:

A análise mostra o verdadeiro caminho pelo qual uma coisa foi descoberta, metodicamente e como que a priori (AT, 7, p. 155). ${ }^{\mathbf{1 1}}$

A análise mostra o verdadeiro caminho pelo qual uma coisa foi metodicamente descoberta e revela como os efeitos dependem das causas (Descartes, 1983c, p. 166; AT, 9-1, p. 121).

A síntese, ao contrário, por um caminho oposto e como que buscado a posteriori (embora a própria prova seja, nesta, amiúde mais a priori que naquela) demonstra, na verdade, claramente o que está contido em suas conclusões, e serve-se de uma longa série de definições, postulados, axiomas, teoremas e problemas (AT, 7. p. 156). ${ }^{12}$

A síntese, ao contrário, por um caminho todo diverso, e como que examinando as causas por seus efeitos (embora a prova que contém seja amiúde também dos efeitos pelas causas), demonstra, na verdade, claramente o que está contido em suas conclusões, e serve-se de uma longa série de definições, postulados, axiomas, teoremas e problemas (Descartes, 1983c, p. 166-7; AT, 9-1, p. 121).

Os intérpretes têm assinalado as diferenças entre as duas versões e tentado compatibilizá-las; contudo, a grande maioria examinou-as sem ter em conta a tradição

\footnotetext{
10 Há poucas alusões explícitas a essa dupla de conceitos ao longo da obra cartesiana, embora o termo "análise" apareça com um pouco mais de frequência que o seu correlato. O termo "síntese" é raríssimo em Descartes. Juntos, os termos aparecem somente mais duas vezes, quando Descartes está comentando sua resolução do problema da quadratura da "roulette" e da determinação da respectiva tangente (cf. AT, 2, p. 394, 4,00). O termo "análise", isoladamente, aparece mais frequentemente.

11 "Analysis veram viam ostendit per quam res methodice et tanquam a priori inventa est" (AT, 7, p. 155).

12 "Synthesis e contra per viam oppositam et tanquam a posteriori quaesitam (etsi saepe ipsa probatio sit in hac magis a priori quam in illa) clare quidem id quod conclusum est demonstrat, ititurque longa definitiorum, petitionum, axiomatum, theorematum, et problematum serie" (AT, 7, p. 156).
} 
matemática na qual o tema se insere (e, portanto, tampouco o texto de Pappus), de sorte que, no final, tiveram de reconhecer a permanência de certas incongruências e a insatisfação diante do resultado obtido. As dificuldades referem-se à utilização dos termos latinos a priori e a posteriori e das expressões francesas correspondentes, que expressam articulações entre as noções de "causa" e de "efeito". Além disso, outra expressão foi em geral ignorada ou interpretada de forma inadequada. Trata-se da expressão "como que" (tanquam), utilizada, por exemplo, para afirmar que a análise, sem ser a priori, é como que a priori, detalhe que se mostrará de fundamental importância. Como se poderá confirmar abaixo, as diferenças centrais entre os textos latino e francês dizem respeito a essas expressões e a algumas nuances que as envolvem.

Comecemos por fixar o significado dos termos a priori e a posteriori. Como diz Alquié, podemos assumir aqui a compreensão tradicional dos termos, dando às expressões o sentido filosófico a elas atribuído desde a Idade Média e ainda comum no século xviı. Um argumento a priori é aquele que "vai da causa ao efeito, do princípio à consequência", enquanto um raciocínio a posteriori é aquele que vai "dos efeitos às causas, das consequências aos princípios" (Alquié, 1987, p. 582, nota 1). Com isso, fica clara a intenção de Clerselier de incorporar esses significados ao texto francês, não havendo nada de aleatório ou de absurdo na tradução, ainda que não seja uma tradução literal. Nesse sentido, o texto francês revelar-se-á enriquecedor por enfatizar noções implícitas no texto latino, e ambos podem ser vistos como complementares. Na verdade, os textos latino e francês mostrar-se-ão tão esclarecedores entre si que, depois de compreendidas suas relações, parecem não mais poder ser compreendidos separadamente, de sorte que se poderia mesmo dizer que os métodos não teriam sido descritos adequadamente senão na forma complementar apresentada.

Assim, a análise, diz o texto latino, é um método de descoberta que procede como se fosse a priori, é um método que simula um procedimento a priori, sem ser rigorosamente a priori. A análise não é a priori, porque não vai dos princípios às consequências, das causas aos efeitos; ela tampouco é um simples procedimento a posteriori. Ela atua como se fosse a priori, visto que procede dos efeitos às causas como se estivesse indo de causas para efeitos. E, portanto, não sendo, rigorosamente, nem a priori nem a posteriori, ela procede como se fosse a priori, simula o procedimento a priori. Em síntese, ela parte dos efeitos e mostra como eles dependem das causas, assumindo os efeitos "como se" fossem causas, simulando-os como causas, embora, mais cedo ou mais tarde, revelarse-ão como efeitos. Nessa perspectiva, a análise começa com os efeitos e mostra de quais causas eles dependem; ela vai, portanto, dos efeitos às causas, assumindo os efeitos a "função" de causas. Nesse sentido, diz o texto latino, a análise não procede $a$ priori, mas como se fosse a priori. 
Sabemos que são as causas que determinam os efeitos e que estes dependem das causas. As causas são logicamente anteriores e primeiras em relação aos efeitos, sempre derivados e posteriores logicamente; e isso não pode ser alterado. Metodologicamente, Descartes evidencia, entretanto, que, além de podermos ir das causas aos efeitos ou dos efeitos às causas, é possível irmos dos efeitos às causas simulando o procedimento contrário. E Descartes não está sozinho nisso. Ele se inspira na análise dos geômetras e dos algebristas, que simulam esse procedimento quando começam a análise com frases como: "suponhamos a solução dada" ou, em termos não matemáticos, "suponhamos os efeitos dados como se fossem causas". Isso significa que, a partir da famosa frase posta em seu início, a análise simula um procedimento a priori, a partir da pressuposição de que aquilo que se procura determinar é dado, de que a solução é dada (cf. Loparic, 1997, p. 103). ${ }^{\mathbf{1 3}}$

O texto francês não é uma tradução literal do texto latino. Ele diz que a análise "revela como os efeitos dependem das causas" e, portanto, afirma que ela vai, não das causas aos efeitos, mas dos efeitos às causas, na tentativa de determiná-las enquanto delas dependem os efeitos. $O$ texto francês não conserva, entretanto, pelo menos de forma evidente, o procedimento de simulação presente no texto latino e, por isso, não determina claramente o papel metodológico dos dados assumidos como ponto de partida, os efeitos, que, no final, acabam por ocupar o seu devido lugar, como consequências. A tradução simplesmente reconhece que a análise parte dos efeitos para chegar à determinação de suas causas, que a análise começa com os efeitos e mostra de quais causas eles dependem. Ela torna mais esclarecedora a direção da causalidade, embora não mantenha o papel metodológico dos efeitos assumidos como dados e conhecidos. E, assim, a versão francesa é apenas menos precisa do que o texto latino, mas em nada discordante dele. ${ }^{\mathbf{1 4}}$

Passemos agora à síntese. Segundo o texto francês, a síntese não começa com os efeitos para inferir as causas, mas, ao contrário, começa com as causas e determina, genericamente, sua verdade por meio de seus efeitos. Em outras palavras, quando deduzimos os efeitos das causas, o sucesso da dedução "confirma" indireta e genericamente a verdade das causas, mas não rigorosamente, visto que de proposições falsas

13 “Descartes não faz mais do que recordar Pappus que diz (...) que a análise problemática começa supondo a incógnita 'como que' dada (e, nesse sentido, a priori) e que a análise teórica trata o teorema a ser provado 'como que' verdadeiro (e, nesse sentido, a priori)". Nossa interpretação segue a interpretação de Loparic.

14. Essa falta de precisão pode ser sanada de três maneiras: (a) pelo fato de a análise, no texto francês, ser chamada também de "resolução" e, com isso, remeter-nos à resolutio dos latinos, procedimento caracterizado por "ambiguidades" semelhantes às que estamos examinando; (b) pela comparação ao texto latino, cuja compreensão não depende do texto francês; (c) pela impossibilidade, dentro do pensamento cartesiano, de a análise ser algum tipo de indução ou algo semelhante. 
(como dizia Aristóteles) é possível extrairmos proposições verdadeiras. Por isso, por testar as causas por meio dos efeitos dela deduzidos, diz Descartes que a síntese procede "como que examinando as causas por seus efeitos". A síntese, portanto, diz o texto francês, mostra quais efeitos se seguem das causas, sem que isso seja equivalente a uma confirmação das causas, porque estas devem poder ser conhecidas independentemente. Se, contudo, os efeitos derivados forem falsos, as causas também serão falsas. Por isso, as causas são "como que" examinadas por seus efeitos.

O texto latino não realça exatamente os mesmos elementos que o francês, ao afirmar que a síntese procede por um caminho "como que buscado a posteriori". A síntese vai das causas aos efeitos; entretanto, como as causas foram derivadas na análise "como se fossem" efeitos, estes são o ponto de partida na síntese, em direção às supostas causas. A síntese não é a posteriori verdadeiramente, mas como que feita a posteriori. Dito de outro modo, como a síntese começa onde a análise termina - análise esta que procedeu "como que a priori" -, ela, ao inverter os passos, procede "como que a posteriori".

As descrições trazem, entre parênteses, por outro lado, observações que parecem contrapor-se ao que acaba de ser dito. Descartes diz, no texto latino, que a prova fornecida pela síntese é, com frequência, mais a priori do que a da análise, e o texto francês afirma que ela é também dos efeitos pelas causas. Com efeito, a síntese parte das causas ou princípios, conhecidos por outros meios, e demonstra consequências ou efeitos que lhe seguem; por isso, a síntese procede de modo a priori, da causa para o efeito, enquanto a análise procede a priori apenas por simulação. Por isso, a síntese é mais a priori que a análise e examina os efeitos pelas causas. Além disso, como à análise não é proibido o uso de elementos a priori ao lado de outros apenas tomados como a priori, à síntese cabe dizer ser ela "amiúde mais a priori" do que a análise, por não fazer uso de elementos a posteriori de espécie alguma (com ou sem simulação). Finalmente, as observações entre parênteses chamam a atenção para o fato de que, no final das contas, é a síntese que é a priori, visto que é ela que estabelecerá o ordenamento e a precedência causais: ela vai das causas aos efeitos. E, assim, dependendo da ênfase dada, análise e síntese podem ser ditas procederem por um "caminho oposto" ou, ao menos, "todo diverso" entre si.

Dito isso, podemos concluir pela compatibilidade entre as versões da descrição cartesiana do método, bem como entre elas e o texto de Pappus. Ainda que Descartes utilize expressões no âmbito da causalidade, distantes do horizonte da ciência matemática, a descrição cartesiana não só é compatível com a pappusiana, como também precisa ser examinada à luz desta, para que adquira sentido e para que sejam desfeitos certos mal-entendidos. 


\section{Conclusĩo}

Embora não tenhamos examinado exemplos ilustrativos do método cartesiano como forma de inseri-lo na tradição dos praticantes da análise, como fizemos em outra ocasião (cf. Battisti, 2002), a mesma conclusão pode ser aqui extraída por meio do exame das descrições do método fornecidas por Pappus e por Descartes. É flagrante a semelhança entre elas, e é a partir da descrição pappusiana que conseguimos dirimir determinados problemas interpretativos da descrição cartesiana e percebemos o caráter complementar entre as duas versões existentes - o texto latino e o texto francês.

O caráter mais marcante da análise é seu movimento contra a corrente, é sua perspectiva de ir de trás para frente. Nesse sentido, ela privilegia o desconhecido, o relativo, o efeito, sem, contudo, negar a primazia epistemológica (e ontológica) do conhecido, do absoluto e da causa. Na análise, não vamos do princípio às consequências, do simples ao complexo, da causa ao efeito, embora sejam o princípio, o simples e a causa que determinem as consequências, o complexo e o efeito. Ela tampouco é um movimento simples no sentido contrário. Como o efeito é efeito de uma causa, partir do efeito significa, para a análise, também antever e utilizar a causa ainda desconhecida, mas necessária em razão do caráter relativo do efeito; por outro lado, embora partamos do efeito, como ele só se torna conhecido pela determinação causal, ele é ainda desconhecido; nesse sentido, causa e efeito são, ambos, conhecidos e desconhecidos sob determinados aspectos, mas o efeito tem a preeminência metodológica de ser dado. A causa continua a ser ela que determina o efeito, mas, por outro lado, este "como que" determina a causa. Os pré-requisitos da homogeneidade garantem esse movimento sem sobressaltos e permitem, em alguma medida, a antecipação pelo pensamento do elemento correspondente. Outros expedientes podem ser utilizados para a efetivação desse jogo, dentre os quais se destacam construções auxiliares e hipóteses.

Meu objetivo, com o presente texto, pretendeu fixar certos pontos fundamentais quanto ao método cartesiano e ao seu fundamento. Primeiro, dado que Descartes elege a análise como seu método, é a partir dos geômetras gregos e de sua tradição que devemos estudá-la e examiná-la. Descartes pertence a essa tradição, como ele confessa expressamente. Em segundo lugar, incluí-lo nessa tradição, contudo, não significa afirmar que seu método seja de natureza matemática. A análise põe às claras o modo de a razão proceder, quando conhece; a matemática, por sua vez, ilustra privilegiadamente, em razão de suas características intrínsecas, a forma de a razão conhecer; por isso, o método cartesiano não permanece preso a essa ciência e pode aspirar à universalidade. Terceiro, a análise mostra a distinção entre o horizonte metodológico e o horizonte epistemológico. As exigências epistemológicas dizem respeito, por exemplo, às rela- 
ções de dependência entre os objetos de um domínio de conhecimento, enquanto as exigências metodológicas dizem respeito ao modo de determinação dessas relações de dependência; e, portanto, embora as primeiras não possam ser desrespeitadas, elas não impõem um direcionamento às últimas. As relações de dependência entre objetos são, em geral, estabelecidas a partir do relativo e do complexo, dada a sua primazia metodológica - por serem dados - em relação ao absoluto e ao simples. É por isso que os Elementos de Euclides foram considerados como o modelo mais perfeito e mais bem acabado do que seja uma ciência certa e evidente (modelo epistemológico), embora não sirvam de modelo metodológico; ao contrário, são acusados de terem omitido seu verdadeiro método de descoberta. Em quarto lugar, um dos modos mais profundos e mais adequados de justificar essa distinção (sem oposição) entre metodologia e epistemologia - e, com isso, justificar o procedimento da análise como um procedimento universal oriundo do modo de operar da razão, quando produz o conhecimento - liga-se à tese cartesiana de que compreender algo é compreender a sua causa e que, portanto, todo algo que se pretenda compreender deve ser considerado como efeito. É constitutivo da razão perguntar-se pela razão das coisas, isto é, pelas causas das coisas. Logo, tudo o que existe apresenta-se como efeito e, como tal, no âmbito do conhecer, clama pela sua causa. As coisas são, antes de tudo, dadas como coisas-efeito. Finalmente, o método, portanto, pode assumir o efeito como dado e proceder de trás para frente (ou para o alto) em busca da causa, como é da essência da análise (pappusiana e cartesiana) assim proceder. É, portanto, a análise (e não a síntese) que executa essa tarefa, e seu fundamento está no axioma que afirma a identidade entre a causa e a razão, causa sive ratio.

César Augusto Battisti

Professor Associado do Curso de Filosofia, Universidade Estadual do Oeste do Paraná, Brasil. cesar.battisti@hotmail.com 


\begin{abstract}
This article examines certain essential points of Cartesian method and its foundation. (1) If Descartes selects analysis as his method - and he does - it is from the ancient tradition of Greek geometers that we should survey it. (2) However, the nature of his method as such is not mathematical: analysis discloses how reason comes to know, as illustrated by the science of geometry. (3) Cartesian thinking distinguishes methodology and epistemology: relationships of dependency among objects are, in general, established starting from relative and complex ones, given their methodological primacy in relation to the absolute and the simple. (4) One of the most fruitful ways to justify this - and, thus, to justify the method of analysis, as far as it is a procedure "against the current" - is connected with the Cartesian thesis that affirms that to understand something is to understand its cause, due to the fact that everything that exists, exists as an effect. (5) It is of the essence of the method of analysis, therefore, that it may assume the effect as given and proceed backwards (or upwards) in search of the cause; and its foundation is the axiom of identity between cause and reason, causa sive ratio.
\end{abstract}

KeYwords $\bullet$ Descartes. Method of analysis. Pappus. Mathematics. Modus operandi of the reason. Causa sive ratio.

\title{
REFERÊNGIAS BIBLIOGRÁFICAS
}

Adam, C. \& Tannery, P. (Ed.). Euvres de Descartes. Paris: Vrin/Centre National Du Livre, 1995-1998. 11 v. (AT).

Alquí, F. Euvres philosophiques de Descartes. Paris: Garnier, 1987. V. 2.

Aristóteles. Ética a Nicômaco. Tradução L. Vallandro, \& G. Bornhein. 3. ed. São Paulo: Nova Gultural, 1987. p. 45-236. (Os pensadores).

Battisti, C. A. O método de análise em Descartes: da resolução de problemas à constituição do sistema do conhecimento. Cascavel/PR: Edunioeste, 2002.

Carraud, V. Causa sive ratio: la raison de la cause, de Suarez à Leibniz. Paris: PUF, 2002.

Descartes, R. Discurso do método. Tradução J. Guinsburg \& B. P. Júnior. 3. ed. São Paulo: Abril Cultural, 1983a, p. 25-71. (Os pensadores).

. Meditações. Tradução J. Guinsburg \& B. P. Júnior. 3. ed. São Paulo: Abril Cultural, 1983b, p. 73 -1422. (Os pensadores).

. Objeções e respostas. Tradução J. Guinsburg \& B. P. Júnior. 3. ed. São Paulo: Abril Cultural, 1983c, p. 14 3-211. (Os pensadores).

. Regras para a direção do espírito. Tradução J. Gama. Lisboa: Edições 70, 1985.

. La geometrie. Adam, C. \& Tannery, P. (Ed.). Euvres de Descartes. Paris: Vrin/Centre National Du Livre, 1995-1998. v. 6, p. $367^{-4} 485$.

Неath, T. L. (Ed.). The works of Archimedes including the method. Chicago: Britannica, 1952.

Hintikka, J. \& Remes, U. A análise geométrica antiga e a lógica moderna. Cadernos de História e Filosofia da Ciência , 4, p. 28-47, 1983.

. The method of analysis. Dordretch: Publishing Company, 1974.

Loparic, Z. Descartes heurístico. Campinas: IFCH/ UNICAMP, 1997.

Pappus de Alexandria. La collection mathématique. Paris: Blanchard, 1982.

VIÈTe. F. In artem analyticen isagoge. In: Hofmann, J. E. (Ed.). Viète. Opera mathematica. Hildesheim/ New York: Verlag, 1970. p. 1-12. 